\title{
Irving Lester Lichtenstein-Surgeon Behind the Gold Standard Procedure for Inguinal Hernia
}

\author{
Kaushik Bhattacharya ${ }^{1}$ (D)
}

Received: 26 April 2021 / Accepted: 12 May 2021

(C) Association of Surgeons of India 2021

Dear Sir,

I read with interest the article by Yelamanchi et al. entitled "Irving Lichtenstein-Pioneer Hernia Surgeon and Civil Rights Champion" [1]. There are few incidences about Irving Lichtenstein which need to be highlighted as he was a legend in hernia surgery who transformed the concept of inguinal hernia surgery in 1964 and introduced the "tension-free hernia repair without disability". His technique not only broke shackles of the traditional two-century-old hernia repair technique of Edoardo Bassini and Earle Byrnes Shouldice but also made it impossible for the newer innovative minimally invasive hernia repair surgery by either laparoscopy or by robots to make inroads and gain the ground. Lichtenstein hernia repair for inguinal repair remains the gold standard procedure still.

Ira M Rutkow commented in the Surgical Clinics of North America that "Lichtenstein was initially considered as iconoclast for his unusual views on inguinal hernioplasty , Lichtenstein is now fairly regarded as a born thinker " [2]. Lichtenstein initiated the concept of "the one-day hernia" where he propagated hernia repair under local anaesthesia without any prolonged bed rest or the after effect of general anaesthesia. He wrote " patient sits up and walk out of the operating room after putting in slippers and robe. Ordinarily he drives home" [3]. His daughter Leslie Lichtenstein remarked after seeing the fast recovery of the procedure as "My dad loved drama. This was dramatic".

In the late 1950s, while working at Cedars-Sinai Medical Centre, Lichtenstein watched a cholecystectomy surgery and as he had just sewn up the wound, the patient began to retch violently. The incision did not reopen which made Lichtenstein realize that a properly sutured wound immediately regained $70 \%$ of its strength and what mattered the most was how it is

Kaushik Bhattacharya

kbhattacharya10@yahoo.com

1 CAPFs Composite Hospital BSF Kadamtala, G616, Uttorayon, Matigara, Siliguri, West Bengal 734010, India being sutured and what suture material is being used. Lichtenstein will make all hernia patient postop cough on table, as they were under local anaesthesia, to check the strength of the repair. In 1964, he stood in front of the thousands of doctors attending an American Medical Association meeting and told them that they were handling hernia patient all wrong.

Lichtenstein reported that his patients had such smooth, painless and quick postop recovery after the procedure that their major concern was convincing their friends that they even had a surgery, and nobody sent them "get well soon cards"!

Finally, the very fact that Lichtenstein tension-free inguinal hernia repair remains the gold standard procedure globally in spite of the latest advances and innovations with minimally invasive route with laparoscopy or by robots reiterates the quote of Ramona Ripston, Executive Director, Southern California American Civil Liberties Union that "In many ways, Irving Lichtenstein was a visionary" [4].

\section{Declarations}

Conflict of interest The author declares no conflict of interest.

\section{References}

1. Yelamanchi R, Agrawal H, Gupta N (2021) Irving Lichtensteinpioneer hernia surgeon and civil rights champion. Indian J Surg. https://doi.org/10.1007/s12262-021-02860-9

2. Rutkow IM (1998) A selective history of groin hernia surgery in the early 19th century. The anatomic atlas of Astley Cooper, Franz Hesselbach, Antonio Scarpa, and Jules-Germain Cloquet. Surg Clin North Am 78:921-940

3. Lichtenstein IL (1966) Immediate ambulation and return to work following herniorrhaphy. Ind Med Surg 35:754-759

4. Oliver M, Irving Lichtenstein; Innovator in civil rights, surgery. Los Angeles Times 2000, June 16. Available at https://www.latimes. com/archives/la-xpm-2000-jun-16-me-41556-story.html

Publisher's Note Springer Nature remains neutral with regard to jurisdictional claims in published maps and institutional affiliations. 